\title{
Analysis of Sustainable Development in Ice and Snow Sports Industry in Heilongjiang Province
}

\author{
Zhao Weiming \\ College of Physical Education, Heihe University, Heihe, 164300, China \\ zhaoweiminghh@126.com
}

Keywords: Ice and snow sports industry; competition; Heilongjiang Province.

\begin{abstract}
Heilongjiang Province is located in the northern part of China. Because of its geographical advantage, Heilongjiang Province should have the cultural background and geographical basis of ice and snow sports. The dimension of northeast China is high, and it is in the sub-cold climate of low temperature and cold all year, so the ice and snow resources are very rich. Under the long-term influence, the northeast area develops the sports enterprise with the aid of the ice and snow resources, and forms the unique ice and snow sports culture. With the growing pace of China's upcoming Winter Olympic Games, the enthusiasm of the government and the people in the development of ice and snow sports is also increasing. Therefore, in view of the current situation of the development of ice and snow sports tourism industry in Heilongjiang Province and the development of resources, the advantages and disadvantages of ice and snow sports tourism in Heilongjiang Province are clarified. To increase cultural publicity, expand the tourist market, promote the sustainable development of ice and snow sports tourism brands in Heilongjiang Province, further improve the construction of related supporting facilities, further strengthen the development of sports ice and snow tourism industry talents, meet the needs of the market, and achieve international integration and other development measures, which provides theoretical support for ice and snow sports tourism in Heilongjiang Province and promotes the rapid development of ice and snow sports tourism industry in Heilongjiang Province.
\end{abstract}

Heilongjiang Province is one of the old industrial bases in Northeast China. Its unique geographical advantages, rich historical culture and special climatic conditions make up the ancient, primitive and magical features of ice and snow sports resources in Heilongjiang Province. Among them, ice and snow tourism sports resources are unique. However, this unique geographical environment is definitely not unique to Heilongjiang Province. Therefore, in the field of ice and snow sports, there are also competitions from other provinces, such as Jilin and Liaoning, and in Heilongjiang Province, there are still many areas that need to be improved, which should be based on their advantages to strengthen the ice and snow sports industry, ice and snow sports to maintain the leading position. According to the natural, social and cultural background of the development of ice and snow sports industry in Heilongjiang Province, the bottleneck of ice and snow sports industry development is discussed, aiming to find some targeted countermeasures.

\section{Introduction}

The Natural, Social and Cultural background of the Development of Ice and Snow Sports Industry in Heilongjiang Province. Heilongjiang Province has big and small Finagling, Zhang Gang caviling and Wanda Mountains, and so on, the mountain area accounts for the province's area of 60, forest area accounts for 4lth, forest coverage is the first in the country. There are more than 100 mountain peaks above $1000 \mathrm{~m}$ above sea level suitable for the construction of large ski resorts, making it the most densely resourced province of skiing tourism in China. Moreover, the winter snow quantity is large, the snow quality is good, the ecological environment is good, the slope is moderate, the snow period is up to 150 days, can last from November to the second year April, spanning the autumn, winter and spring three seasons. Around Harbin, there are large ski resorts led 
by Yale, Ellingham, Jihad, Ping Shan Sheila, Huainan Jump and Revue Gorge. The Mudanjiang River has a ski resort represented by the Wang Road ski resorts. Even on the side of the Heehaw River lying on a bull lake on the border line, two years ago, the Heehaw Far East International Ski Resort with SSS class was built. It is the skiing in Heilongjiang that plays an international card. Heilongjiang Province has more than 150 ski tracks, with a total length of nearly 150,000 extended meters, more than 120 cableways and 35,000 snows.

Rich ice and snow sports culture. With the advantage of natural resources, the Heilongjiang Provincial Government led the publicity of ice tourism, starting from 1963 years to establish ice lantern garden, and 1985 years to hold ice and snow festival and in 1998 to build a world of snow and ice. The combination of ice sculpture art and snow sculpture art, ice sports and snow sports, ice sports and national fitness gradually formed a rare style and advantage in the world. Harbin ice and snow festival, Heilongjiang international ski festival, Qiqihar ken dung cultural festival, Mudanjiang snow town tourism festival and so on at home and abroad all enjoy high levels of transcripts. Skating, skiing tourism and the annual Harbin Ice and Snow Festival, Qiqihar Guangdong Cultural Festival organic integration together, greatly improve the ice and snow sports culture in Heilongjiang Province. With the increasing of people's economic consciousness, ice and snow sports have become ice and snow sports culture with rich connotations of ice and snow science, ice and snow art, ice and snow tourism, ice and snow economy and trade, ice and snow diet, ice and snow commodities and so on. The ice and snow sports culture has promoted the social progress, the economic growth, and has formed the "ice and snow build stage, the economy sings the drama" the gratifying scene.

\section{Development Strategy of Ice and Snow Sports Industry}

We should make a scientific overall plan and increase supply and demand. Snow is an important part of the development of ice and snow industry in Heilongjiang Province. With the rapid increase of skiing enthusiasts, the snow-skating fields in Heilongjiang Province are springing up everywhere. However, some ski resorts are driven by interests, blindly seeking to become stronger and bigger, blindly competing with each other and rushing onto the horse. They do not fully meet the requirements in such aspects as site selection, site construction, safety protection, management, etc. Among them, the slope is not suitable and the snow way is narrow. The lack of timely maintenance of snow ways and the lack of rescue facilities are common problems. This is precisely because the government functions lack of scientific coordination and guidance on the construction of ski resorts, resulting in uneven scale and construction of ski resorts in Heilongjiang Province. The order of fish is mixed. Overdevelopment leads to oversupply and disconnect between supply and demand. In addition, the lack of scientific argumentation and market research will often lead to the waste of funds and man-made destruction of the natural environment. At present, the small and medium-sized snowfields in some counties and cities of Heilongjiang Province, due to poor management and disorderly competition, have, on the one hand, resulted in a waste of local financial resources; on the other hand, they have destroyed natural resources. For example, soil erosion and environmental pollution have had a certain negative impact on the lives of local people. This phenomenon should be paid enough attention by the government, and the overall development of ski resorts resources should not only reduce the construction of small ski resorts. But also to create high-grade fine ski resort, promote the ice and snow industry healthy cycle of steady development.

To constantly improve infrastructure. A mature ice and snow sports industry should not only have sufficient resources but also complete related facilities. While building boutique tourist attractions, it should create convenient transportation and comfortable accommodation for tourists. Delicious catering, essential medical care and Internet services are essential links. In recent years, in order to promote the great development of the ice and snow sports industry, Heilongjiang Province has increased its investment in the infrastructure of ice and snow tourism, such as adding snowboards, snow tracks, improving the snowfield environment, increasing the protective function, and so on, to a certain extent, has improved the facility environment .However, some large snow 
spots face a steady flow of tourists during the holidays, the existing reception capacity is very tight, equipment shortage, especially cannot guarantee the demand of high-end tourists. With the rapid development of economy, people's demand for skiing is diverse, and the current ski resort is limited to the beginning, middle and high grade, the world's popular cross-country skiing simply cannot be opened, resulting in these high-end users have to go to the country. Skiing in a mature snowfield leads to the loss of a large number of tourists. Therefore, it is necessary to improve the infrastructure in time, contain the momentum, and prevent the formation of bad circulation.

Strengthen professional talents. The key to the sustainable development of ice and snow sports industry and the promotion of competitiveness are specialized decision-making talents and special service practitioners. At present, the development of ice and snow human resources and ice sports in Heilongjiang Province is very unscientific. Many people engaged in the ice and snow sports industry are retired athletes or coaches, and most of them lack theoretical knowledge. The knowledge of ice and snow sports management is not systematic, and the understanding of ice and snow industry and economy is not deep enough .But to understand ice and snow sports, and to understand the professional management, management and decision type of industrial management are very scarce. At the same time, some Lesser Snow field that do not have the necessary conditions, their coaches' professional accomplishment and ability are not up to the standards of employment. Some go to work in a hurry after simple training. The theoretical level and cultural quality are generally not high. They can neither guide tourists scientifically, nor can they ensure their safety. As a result, tourists are disappointed and come back. In the long run, this will weaken the competitiveness between Heilongjiang Province and other provinces where ice and snow industry is rising, and eventually lead to the loss of market share. Strengthening the professional personnel is the restriction of the ice and snow industry in Heilongjiang Province.

Heilongjiang province should make full use of modern information transmission system such as radio, television, newspaper, internet, etc. widely publicize and report , increase cultural propaganda, snow culture, art, sports, etc. build the image of ice and snow tourism in Heilongjiang Province, expand the tourist market and manage the new system .In order to link up with the outside market, the domestic market and the foreign market, although Heilongjiang still faces many difficulties in developing ice and snow tourism industry, with the implementation of the strategy of revitalizing the old industrial base in Northeast China, To let more people outside the province and abroad to understand Heilongjiang Province, let the people understand the ice and snow culture in Heilongjiang. Let the event become a festival for ordinary people. In terms of the positioning of the tourist market, the domestic and development markets are mainly based on the province, focusing on the southeast coastal areas, and at the same time further improving the related facilities to build ice and snow sports projects that integrate ice and snow with art. It is a comprehensive industry to increase the production of snow and ice tourism. We should follow the development of various types, diversified functions, multi-modes of management, and vigorously develop transportation, catering and accommodation propaganda and public relations. Attach importance to the sustainable development of the natural environment and the protection of the bad environment of the human society, inherit and innovate the development, further improve the accommodation, electric power, communication and other undertakings, embody the local characteristics of Heilongjiang Province, realize the ice and snow tourism in Heilongjiang Province. The hardware and software, service quality and construction, make the greatest efforts to meet the tourists in various aspects of ice and snow sports tourism life needs. Make full use of existing manufacturing base, actively support the enterprises to increase R \& D and production efforts, realize the sustainable development of snow sports tourism new leap.

\section{Summary}

Through more than ten years of meticulous cultivation, Heilongjiang Province has brought up the advantages of the country's famous ski tourism brand, and created ice and snow sports tourism, ice and snow art, sports, amusement, tourism, food research and other ice and snow culture. However, there are still disadvantages such as insufficient depth of development of tourism market, 
low efficiency, and urgent improvement of tourism service quality, poor connection of tourism industry chain and lack of talents. Under the guidance of the government, through market operation and public participation, we should establish a two-way management mode between the government and the market. Through scientific planning, rational distribution, the government and the functional departments should optimize the allocation of resources and production factors. Promote the scale of enterprises, intensive operation, create good, loose management, Heilongjiang Province ice and snow tourism better development. The development pattern of "one core, one axis and four lines" is constructed, the legal and economic environment is obeyed, the planning of snow resources is strengthened, and the sustainable development of brand superiority is protected. Development can embody ice and snow and human tradition, ice and snow and sports, further improve related facilities to build ice and snow sports projects that integrate ice and snow with art, increase tourism industry of snow and ice tourism is a comprehensive industry, and should follow the development of various types. Diversification of functions, multi-mode of management, vigorous development of transportation, promotion and public relations of catering industry, emphasis on the sustainable development of the natural environment and protection of the social environment, inheritance and innovation, and further improvement Accommodation, electricity, communications and other undertakings, reflect the local characteristics of Heilongjiang Province. To increase the comprehensive service quality and construction of snow tourism hardware and software, to realize the freezing point in Heilongjiang Province, and to make the best efforts to meet the needs of tourists in the life of ice and snow sports tourism. Make full use of the existing manufacturing industry to realize the new leapfrog sustainable development of ice and snow sports tourism. Actively support related enterprises to increase R \& D and production, so that the scale of enterprises continues to expand.

Heilongjiang Province is rich in ice and snow sports resources and is a province with better development of ice and snow sports and ice sports industry in China. Affected by the development of ice and snow sports in Heber, Jilin and Xinjiang in recent years, the development advantage of ice and snow sports industry in Heilongjiang Province is fading gradually. Therefore, we should think about the development of ice and snow sports industry in Heilongjiang Province from the macroscopic angle of industrial layout, analyze the present situation of ice and snow sports industry in Heilongjiang Province, and discuss the overall influencing factors. Select the advantage ice and snow sports industry of Heilongjiang Province, and then give priority to develop the ice and snow sports industry with comparative advantage, and actively cultivate the latent advantage ice and snow sports industry. In order to promote the sustainable development of ice and snow sports industry in Heilongjiang Province from the macro strategic layout, the development of ice and snow sports industry without advantages should be developed slowly.

\section{Acknowledgements}

A Planned Project on a Study of philosophical and Social Science of Heilongjiang Province: A Study of the Structure Optimization for Ice-sonw Sports Industry and Applied Talent Training of Heilongjiang Province (16TYE02).

\section{References}

[1] Yang Yong e.g., Snow sports, People's Sports press, 2003.

[2] Z. Jun. f, Skiing is in China, Beijing physical Education University Press, 2017.

[3] C. J. h, Ski Tourism Management, Heilongjiang University Press, 2017.

[4] Extracurricular, ice and snow sports skills, China Society Press, 2009

[5] H. Y.L, Z. K, a feasibility study on the establishment of "field survival training" experimental base for college students in the Zhoushan archipelago [J], Journal of Beijing Sport University, 03 2006. 
[6] S. Wan L, Ski-ice dancer, Taiwan Press, 2014.

[7] J. Li, Study on the practice of College Students' field living and life training [J], Journal of Beijing Sport University, 02 phase of 2005.

[8] Birkel DA, Edgren L, Hatha sports: improved vital capacity of college Students [J], A1tern Ther Heal Th Med.2000Nov, 6(6):55-63. 